\title{
Alien arthropod predators and parasitoids: an ecological approach
}

\author{
Helen E. Roy • Patrick De Clercq • \\ Lori-Jayne Lawson Handley • Remy L. Poland • \\ John J. Sloggett $\cdot$ Eric Wajnberg
}

Received: 20 May 2011/Accepted: 6 June 2011

(C) International Organization for Biological Control (IOBC) 2011

\begin{abstract}
Invasive alien species (IAS) coupled with climate change have been referred to as a "deadly duo". Until recently research on invasion biology has centred mainly on alien plants and vertebrates, despite the numerical dominance of alien arthropods. Arthropods are the largest group of IAS worldwide and many can play a beneficial role, particularly in
\end{abstract}

Handling Editor: Eric Wajnberg

H. E. Roy $(\square)$

NERC Centre for Ecology \& Hydrology, Benson Lane, Crowmarsh Gifford, Wallingford, Oxfordshire OX10 8EF, UK

e-mail: hele@ceh.ac.uk

P. De Clercq

Department of Crop Protection, Ghent University,

Coupure Links 653, 9000 Ghent, Belgium

L.-J. Lawson Handley

Evolutionary Biology Group, Department

of Biological Sciences, The University of Hull,

Kingston-Upon-Hull HU6 7RX, UK

R. L. Poland

Clifton College, 32 College Road, Clifton,

Bristol BS8 3JH, UK

J. J. Sloggett

Kronenburgwerf 58, 4812 XR Breda, The Netherlands

E. Wajnberg

INRA, 400 Route des Chappes BP 167,

06903 Sophia Antipolis Cedex, France controlling insect and mite pests. Indeed, 1590 terrestrial arthropod species have been identified as alien to Europe but only a fraction has been shown to cause either an ecological or economical impact, yet knowledge is severely limited by a paucity of data. The IOBC/WPRS Working Group "Benefits and Risks of Exotic Biological Control Agents" developed the theme of this special issue to begin to address the limitations in understanding of this important research area. It represents a timely synthesis of current ecological knowledge and research on alien arthropod predators and parasitoids.

Keywords Invasive alien species - Arthropods · Parasitoids · Predators · Modelling · Molecular tools · Impacts $\cdot$ Pathways $\cdot$ Biological control

\section{Introduction}

The Millennium Ecosystem Assessment (2005) designated invasive alien species, alongside climate change, habitat destruction, pollution and overexploitation, as one of the main causes of global biodiversity loss. More recently, invasive alien species (IAS), coupled with climate change were referred to as a "deadly duo" at the Nagoya Biodiversity Summit (2010). Sarah Simons, Executive Director of the Global Invasive Species Programme (GISP) stated 
that “The dangers posed by this 'deadly duo' cannot be overestimated. Each driver poses an enormous threat to biodiversity and human livelihoods but now, evidence is rapidly emerging which shows that climate change is compounding the already devastating effects of invasive species, resulting in a downward spiral with increasingly dire consequences."

Alien (or non-native, non-indigenous, foreign, exotic, introduced) species are defined by the Convention on Biological Diversity (CBD: http://www. cbd.int) as "a species, subspecies or lower taxon (such as a variety, race, provenance or stock), introduced outside its natural past or present distribution, which includes any part, gametes, seeds, eggs, or propagules of such species that might survive and subsequently reproduce" (COP 6 , decision VI/23) and invasive alien species (IAS) as "an alien species whose introduction and/or spread threaten biological diversity" (COP 6, decision VI/23). Throughout this special issue we align to these definitions but extend the concept of an IAS to include threats to society and the economy. Additionally, we acknowledge that the threat IAS pose to biological diversity has far-reaching consequences, including impacts to ecosystem processes.

Alien species, and particularly the subset that are considered invasive, have received increasing attention in recent years. This has been, in part, a response to the dramatic increase in the number of alien species arriving in countries over the last 100 years. There are a number of international agreements which recognise the negative effects of IAS and reflect the growing concerns of many people. For example, European countries now have obligations in relation to alien species and must: "strictly control the introduction of non-indigenous species" (Bern Convention on the Conservation of European Wildlife \& Natural Habitats) and "eradicate those alien species which threaten ecosystems, habitats or species" (UN Convention on Biological Diversity). Many countries across Europe have developed strategies in relation to IAS and there is a move to consider these through a unified European-wide approach.

The Guiding Principles of the CBD advocate a three-tiered approach (prevention, eradication and control) which is widely adopted across the globe. It is recognised that an important first step in developing a strategy for addressing the problems posed by IAS is to document the alien species already present in countries, as well as those likely to arrive (perhaps because they have been introduced into a neighbouring country). DAISIE (Delivering Alien Invasive Species Inventory for Europe), a scientific project funded by the European Commission, allows users to search for information on the 10,961 alien species currently recorded in Europe, and highlights those alien species that are of greatest concern in Europe through a list called "100 of the worst" (http://www.europe-aliens.org). A web-based platform GISD (Global Invasive Species Database) provides an opportunity to link information sources on alien species globally. Such information forms the basis on which to develop risk assessments to underpin appropriate action for the most ecologically and economically costly IAS.

\section{From biological control to invasion}

The issues relating to IAS have an alternative context when considering biological control practices developed for use in agricultural ecosystems. First of all, such agroecosystems are usually highly simplified environments, with temporal and spatial heterogeneity in which accidentally introduced IAS can easily spread and rapidly become noxious pests. Furthermore, releasing a natural enemy (such as a predator or parasite) for the classical biological control of such pests can be viewed as a desirable biological invasion because in such a case there are, hopefully, some beneficial outcomes. Hence, an invasion biology approach is relevant to improve the efficacy of biological control programmes, for example to estimate accurately the probability of success or failure of an exotic (=alien) natural enemy for the control of an alien pest.

Alien arthropod predators and parasites provide a unique group of organisms for exploring themes in invasion biology. Arthropods are the largest group of IAS worldwide and many can play a beneficial role, particularly in controlling insect and mite pests (Engelkes and Mills 2011). Up to now, research on invasion biology has centred mainly on alien plants and vertebrates, despite the numerical dominance of alien arthropods (Kenis and Branco 2010). Indeed, 1590 terrestrial arthropod species have been identified as alien to Europe. Of these, 513 are 
predators or parasites (Roy et al. 2011b). Only a fraction of alien predatory and parasitic arthropods in Europe have been shown to cause either an ecological or economical impact, yet knowledge is severely limited by a paucity of data. The IOBC/WPRS Working Group "Benefits and Risks of Exotic Biological Control Agents" developed the theme of this book, which is a special issue of BioControl, to begin to address the limitations in understanding of this important research area. It represents a timely synthesis of current ecological knowledge and research on alien arthropod predators and parasitoids.

\section{Determining invasion success}

Arguments developed in the first paper highlight the importance of different factors influencing the success of an IAS at successive stages of the invasion process (Engelkes and Mills 2011). The attributes of successful IAS have indeed long been investigated and debated in an attempt to predict the likelihood of a given species becoming an IAS. For example, anthropogenic factors are extremely important in the arrival stage, whereas abiotic and biotic factors, particularly propagule pressure, determine success in the establishment phase. It is still extremely difficult to predict the outcome of invasion by an alien species because of the lack of data (Roy et al. 2011b), but consideration of multitrophic interactions should be a research priority (Engelkes and Mills 2011).

Evans et al. (2011a) expand upon the importance of anthropogenic factors and particularly human-mediated environmental change. A landscape approach is particularly pertinent for species which by definition spread extensively. The complex and dynamic interactions between climatic and landscape factors can appear bewildering, but the ecological, economical and societal consequences of IAS necessitate detailed consideration of the ecology of invasions. Molecular tools will undoubtedly make a major contribution to unravelling such complex interactions, and this is the topic of the next paper (Lawson Handley et al. 2011). Historically, molecular techniques have been used to explore fundamental aspects of the invasion process, including determining the origin of source populations and the genetic profile of founding populations. In recent years, the potential of innovative molecular techniques has been more fully exploited by invasion biologists and intriguing insights into the dispersal of IAS have been revealed (Lawson Handley et al. 2011). The combination of molecular genetics coupled with network modelling provides an extremely powerful approach to investigating community interactions from predator and parasite to prey and host, and this is the subject addressed by the next paper (Aebi et al. 2011). Indeed, DNA based approaches to detecting intra-guild predation in the field are yielding fascinating but worrying insights into a number of IAS. Invasions are heralded by evolutionary geneticists as providing unique opportunities for examining evolutionary theory which will consequently enhance the broad understanding of invasion biology.

Dispersal obviously remains a fundamental component of all invasion processes influencing the establishment and subsequent spread of an IAS. Heimpel and Asplen (2011) describe the "Goldilocks Hypothesis" in the context of optimizing biological strategies: intermediate dispersal distances maximize the probability of a biological control agent establishing while minimizing the potential impacts attributed to extensive spread. The importance of considering dispersal potential as part of a risk assessment process, coupled with the possibility of manipulating either the biological control agent or the landscape into which it is released is now recognized (Heimpel and Asplen 2011).

The distribution and abundance of an IAS is affected by the landscape (so called bottom-up processes), biological attributes of the IAS (including dispersal and reproduction) and by natural enemies (so called top-down processes). The importance of these in determining the ultimate success of an IAS is widely debated. The Enemy Release Hypothesis (ERH) predicts that an alien species introduced into a new locality should experience a decrease in regulation by natural enemies which will lead to its proliferation and spread, and this is then discussed by Roy et al. (2011a). However, at the centre of this theory is the assumption that top-down processes are critical in limiting the population growth of an IAS. Critical analysis reveals that there are as many studies refuting the ERH as there are in support of it (Roy et al. 2011a), but there is a distinct lack of comparative research on the regulation of IAS in both the native and invaded range (Torchin et al. 2003). Roy et al. (2011a) highlight the relevance of statistical modelling in 
conjunction with innovative molecular approaches for exploring ERH.

Invertebrate IAS are widely attributed to adversely affect biodiversity (Kenis et al. 2009) but the direct and indirect effects are difficult to quantify (Kindlmann et al. 2011). It is equally difficult to attribute traits as characteristic of successful invaders, indeed this has been the subject of much debate. Kindlmann et al. (2011) focus their review on the ecological effects of invasive alien insect predators that feed on pest insects, acknowledging the relevance to biological control. They conclude that evidence on the negative effects of IAS in terms of decreased abundance of native predators is scarce (Brown et al. 2011a), acknowledging that detecting the effect of long-lived IAS on communities consisting of long-lived native predators and short-lived prey is hard to detect. The evidence of invasive alien insects exerting effects on native communities is growing and exemplified by landmark field studies in this field (Adriaens et al. 2008; Brown et al. 2011b). However, it is clearly the case that further research on the effects of IAS, particularly invertebrates, on biodiversity is required.

\section{An inventory of invasive arthropod predators and parasites}

There has been a proliferation of theories in relation to invasion biology in recent years but these can only be examined in detail by understanding the ecology of IAS. DAISIE provides a unique resource for examining the taxonomic breadth of IAS across Europe over time (DAISIE 2009). Roy et al. (2011a, b) have thus scrutinized the DAISIE database for information on terrestrial arthropod predators and parasitoids. The dramatic increase in the establishment of alien arthropods across Europe is linked to the expansion of global trade and predicted to continue for decades to come and this is discussed in detail by Roy et al. (2011b). Historically, many alien predators and parasitoids were introduced intentionally as biological control agents, but in Europe and other continents, more stringent regulations (Hunt et al. 2007) have reversed this trend in favour of unintentional translocations (Roy et al. 2011b), whereby the arrival of an alien species is an accidental introduction, for example a stowaway or contaminant. It is interesting to note that many of the arthropod alien species are found in urban or synanthropic habitats which perhaps supports the theory that natural communities are more resilient to invasion (Shea and Chesson 2002). However, it is equally possible that there is a paucity of information from natural systems, a message reflected throughout this special issue.

Concerning Hymenoptera, the Vespidae (wasps) have been documented as IAS with major ecological and societal impacts. Beggs et al. (2011) thus review the ecological effects and potential for management of invasive alien Vespidae from a global perspective. Of the 34 alien Vespidae, only seven species are considered as IAS. Interestingly, these are all eusocial species (Beggs et al. 2011). There are parallels in the ecology and control of both the Formicidae and Vespidae which link to attributes associated with eusociality, particularly reproductive strategies, enabling high abundance to be achieved rapidly (Beggs et al. 2011; Rabitsch 2011). Therefore, it is perhaps not surprising that although eusocial insects globally represent only a small proportion of all insect species (about 2\%), more than $24 \%$ of insect species considered to be IAS are eusocial (Beggs et al. 2011).

The parasitic Hymenoptera provide an interesting contrast to their eusocial counterparts. Gibbs et al. (2011) thus provide a detailed account of the invasion history of the chestnut gall wasp Dryocosmus kuriphilus (Hymenoptera: Cynipidae), and assess the use of the parasitoid wasp Torymus sinensis Kamijo (Hymenoptera: Torymidae) for control. Classical and augmentative biological control involves the release of an introduced biological control agent (predator, parasitoid or pathogen) to control an introduced pest. Both biological control strategies present an interesting paradox in invasion biology whereby the unintentional introduction of an alien pest insect is coupled with the intentional introduction of an alien control agent. Classical and augmentative biological control have been employed globally and more than 2000 species of exotic (=alien) natural enemy have been released worldwide (van Lenteren et al. 2006) resulting in the control of 165 pest species. The vast majority of biological control agents do not present ecological or societal problems and are beneficial to the economy in most of the cases (De Clercq et al. 2011). However, a small number of exotic biological control agents have been 
implicated in non-target unintentional effects (Wajnberg et al. 2001). Therefore, risk assessment is considered fundamental prior to the introduction of a biological control agent (see also De Clercq et al. 2011). Gibbs et al. (2011) apply two risk assessment methods to assess the environmental risks associated with the release of Torymus sinensis in central Europe. The risk assessment methods highlight gaps in knowledge in relation to the ecology of $T$. sinensis. Conversely, consideration of the risks posed by release of $T$. sinensis reveals gaps in the risk assessment process principally in failing to acknowledge indirect effects.

There have been few documented cases of impacts attributable to alien arachnids (Nedved et al. 2011). Nevertheless the ecology of spiders (Araneae), harvestmen (Opiliones), and the Schizomida alien to Europe is fascinating and provides insights into pathways of introduction which are relevant across other taxa. Additionally a number of species are dramatically expanding their distribution range in Europe and the mechanisms behind this spread are described within this special issue (Nedved et al. 2011).

Of all the predatory arthropods it is the alien Formicidae (ants) that appear to have the greatest impact on biodiversity (Rabitsch 2011). The negative effects of alien ants extend beyond declines in biodiversity to societal impacts (Kenis et al. 2009) and, perhaps more importantly ecosystem processes and functions. Rabitsch (2011), inspired by "The Hitchhiker's Guide to the Galaxy", presents a unique interpretation of ant invasion biology. The establishment of an alien ant species can be catastrophic and so interception is deemed to be critical but there are a number of innovative and promising control methods that could be employed to limit the threat posed by alien ants (Rabitsch 2011), the most intriguing of which are the maternally-inherited bacterial endosymbionts such as Wolbachia. However, successful control will be dependent on an integrative approach and Rabitsch (2011) outlines a number of potential strategies for regulating alien ant populations.

Alien crustaceans have also received considerable attention, perhaps because of the devastating effects they have on native communities within their invaded range (Haenfling et al. 2011). They are widely considered to be the most successful of all aquatic IAS and their impacts are far-reaching. Many consider the detrimental effects of an IAS on biodiversity to be unacceptable, and this is recognized in the UN Convention on Biological Diversity definition of an IAS. However, alien crustaceans not only exert negative effects on biodiversity but also alter ecosystem functioning by changing energy flux and nutrient cycling, thus impacting on critical ecosystem services such as fish yields and water quality (Haenfling et al. 2011).

The Coccinellidae (ladybirds) are often considered as flagships for biological control (Roy et al. 2011). There has been a long history of releasing alien coccinellids for the control of pest insects worldwide (Evans et al. 2011b). The 11 species of alien ladybird in Europe were all introduced as biological control agents (Roy and Migeon 2010), but only one of these, $H$. axyridis is considered to be an IAS. Evans et al. (2011b) thus provide a comprehensive overview of the history of introductions of coccinellids worldwide. In addition, other alien Coleoptera are briefly considered and the authors conclude that although alien Coccinellidae have received the most research attention, many other Coleoptera have the potential to invade new regions and exert ecological effects (Evans et al. 2011b).

\section{From biological control to invasion: the ladybird Harmonia axyridis as model species}

Harmonia axyridis (Pallas) Coleoptera: Coccinellidae) is undoubtedly responsible for the dominance of literature on invasive alien coccinellids compared to other Coleoptera. In recognition of the global interest in H. axyridis a special issue of the journal BioControl provided a comprehensive overview of research on this species (Roy and Wajnberg 2008). The three years since this publication have seen both further spread of $H$. axyridis and advances in knowledge and understanding of the ecology of $H$. axyridis. Therefore, four papers in this current special issue focus on $H$. axyridis, which continues to be a model species for understanding the path from biological control agent to IAS.

The first describes the status of $H$. axyridis within its native range. Studies on IAS often focus on the ecology of the invader within the introduced range and the native range is neglected. This is undoubtedly the case for many alien invertebrates and is 
exemplified by the wealth of research on $H$. axyridis in the invaded range compared to the paucity of information on this species within the native range (Osawa 2011). Osawa (2011) provides a critical review of the ecology of $H$. axyridis across Asia and highlights a negative correlation between $H$. axyridis and diversity of the aphidophagous community. The coexistence of $H$. axyridis and other species is reported to depend on habitat heterogeneity.

The spread of this ladybird from Asia to four additional continents is conveyed through a timely update on the status of $H$. axyridis globally (Adriaens et al. 2008; Brown et al. 2008a, b; Brown et al. 2011a; Koch and Galvan 2008). Both long-range dispersal, mainly through introduction as a biological control agent or by accidental introduction as a produce (for example, flowers and fruit) contaminant, and short-range dispersal have been important mechanisms for the spread of $H$. axyridis (Brown et al. 2011a). Harmonia axyridis is documented as established in 37 countries and molecular analysis has revealed the origins of the European and South American populations (Brown et al. 2011a).

The spectacular spread of $H$. axyridis has been a source of intrigue for many ecologists (Lombaert et al. 2008; Poutsma et al. 2008; Soares et al. 2008). Harmonia axyridis is considered to be one of the fastest spreading alien insects in Europe (Majerus et al. 2006). Evidence suggests that a number of key attributes of $H$. axyridis are associated with invasion success. Harmonia axyridis possesses chemical defences which are effective against predation and parasitism by a number of other species, providing an additional advantage to this IAS, as explained by Sloggett et al. (2011). Intra-guild predation is prevalent amongst generalist natural enemies and $H$. axyridis is a particularly effective intra-guild predator (Aebi et al. 2011; Burgio et al. 2008; Ingels and De Clercq 2011; Pell et al. 2008; Ware and Majerus 2008) but less commonly an intra-guild prey (Sloggett et al. 2011). Indeed, potential control strategies for $H$. axyridis are limited (Kenis et al. 2008; Koyama and Majerus 2008; Roy et al. 2008) but infochemicals (attractants and repellents) show promise in this regard (Sloggett et al. 2011).

The enemy release hypothesis (ERH) could explain the rapid spread of IAS such as $H$. axyridis (Roy et al. 2011a). In recent years much has been revealed about the interactions between $H$. axyridis and coccinellid natural enemies, particularly parasites and pathogens, found within the introduced range (Roy et al. 2011c). However, empirical evidence in support of enemy release is lacking. Roy et al. (2011c) highlight the importance of research, within a life-table framework, comparing life history traits of $H$. axyridis in both the native and introduced ranges.

\section{Economic and ecological benefits of alien arthropods}

Much of the focus of this special issue has been on the potential of arthropod predators and parasitoids to become IAS. However, it should not be forgotten that the use of alien arthropods in classical and augmentative biological control programmes can yield economic and ecological benefits. The concluding contribution to this special issue thus explores the benefits and risks of exotic biological control agents in detail (De Clercq et al. 2011). The need for further research to counter the paucity of information on alien arthropods is a prevailing message throughout this special issue. Addressing the gaps in ecological knowledge is particularly important to enable objective and thorough risk assessments to be undertaken (De Clercq et al. 2011). Understanding invasion biology, and the dynamics of biological control practices, requires a multidisciplinary approach, embracing and integrating all the research tools at our disposal, particularly modern molecular and modelling techniques. IAS are a global problem and a unified approach is eminently the most prudent way forward. The collaborative papers within this special issue highlight the tremendous benefits of scientists working together to further understanding of the ecology of IAS but also, ultimately, to assist in the development of strategic approaches to address the problems they pose.

Acknowledgments The authors would like to thank all the contributors to this special issue of BioControl. The enthusiasm of the IOBC/WPRS Working Group "Benefits and Risks of Exotic Biological Control Agents" is immensely appreciated. The goal of the working group is to offer a forum for exchange of information and to stimulate contacts and cooperation between scientists. We would like to thank Franz Bigler and the IOBC/WPRS executive committee and council for their encouragement and guidance. HER is funded through the Centre for Ecology \& Hydrology (Natural Environmental Research Council (NERC). HER is also funded by the Joint 
Nature Conservation Committee (JNCC). HER also receives funding from the Department for Environment, Food and Rural Affairs (Defra) for work on the GB Non-Native Species Information Portal.

\section{References}

Adriaens T, Gomez GMY, Maes D (2008) Invasion history, habitat preferences and phenology of the invasive ladybird Harmonia axyridis in Belgium. BioControl 53:69-88

Aebi A, Brown PMJ, De Clercq P, Hautier L, Howe A, Ingels B, Ravn H-P, Sloggett JJ, Zindel R, Thomas (2011) APM Detecting arthropod intraguild predation in the field. BioControl. doi:10.1007/s10526-011-9378-2

Assessment ME (2005) Ecosystems and human well-being: synthesis. Island Press, Washington, DC

Beggs JR, Brockerhoff EG, Corley JC, Kenis M, Masciocchi M, Muller F, Rome Q, Villemant C (2011) Ecological effects and management of invasive alien Vespidae. BioControl. doi:10.1007/s10526-011-9389-z

Brown P, Frost R, Doberski J, Sparks T, Harrington R, Roy H (2011a) Decline in native ladybirds in response to the arrival of Harmonia axyridis (Coleoptera: Coccinellidae): early evidence from England. Ecol Entomol 36:231-240

Brown PMJ, Adriaens T, Bathon H, Cuppen J, Goldarazena A, Hagg T, Kenis M, Klausnitzer BEM, Kovar I, Loomans AJM, Majerus MEN, Nedved O, Pedersen J, Rabitsch W, Roy HE, Ternois V, Zakharov IA, Roy DB (2008a) Harmonia axyridis in Europe: spread and distribution of a non-native coccinellid. BioControl 53:5-21

Brown PMJ, Roy HE, Rothery P, Roy DB, Ware RL, Majerus MEN (2008b) Harmonia axyridis in Great Britain: analysis of the spread and distribution of a non-native coccinellid. BioControl 53:55-67

Brown PMJ, Thomas CE, Lombaert E, Jeffries DL, Estoup A, Lawson Handley L-J (2011) The global spread of Harmonia axyridis: (Coleoptera: Coccinellidae): distribution, dispersal and routes of invasion. BioControl. doi:10.1007/ s10526-011-9379-1

Burgio G, Lanzoni A, Accinelli G, Maini S (2008) Estimation of mortality by entomophages on exotic Harmonia axyridis versus native Adalia bipunctata in semi-field conditions in northern Italy. BioControl 53:277-287

DAISIE (2009) Handbook of alien species in Europe. Springer, Dordrecht

De Clercq P, Mason PG, Babendreier D (2011) Benefits and risks of exotic biological control agents. BioControl. doi: 10.1007/s10526-011-9372-8

Engelkes T, Mills NJ (2011) A conceptual framework for understanding arthropod predator and parasitoid invasions. BioControl. doi:10.1007/s10526-011-9377-3

Evans EW, Comont R, Rabitsch W (2011a) Alien arthropod predators and parasitoids: interactions with the environment. BioControl. doi:10.1007/s10526-011-9375-5

Evans EW, Soares AO, Yasuda H (2011b) Invasions by ladybugs, ladybirds, and other predatory beetles. BioControl. doi:10.1007/s10526-011-9374-6
Gibbs M, Schonrogge K, Alma A, Melika G, Quacchia A, Stone GN, Aebi A (2011) Torymus sinensis: a viable management option for the biological control of Dryocosmus kuriphilus in Europe? BioControl. doi:10.1007/ s10526-011-9364-8

Haenfling B, Edwards F and Gherardi F (2011) Invasive alien crustacea: dispersal, establishment, impact and control. BioControl. doi:10.1007/s10526-011-9380-8

Heimpel GE, Asplen MK (2011) A 'Goldilocks' hypothesis for dispersal of biological control agents. BioControl. doi: 10.1007/s10526-011-9381-7

Hunt EJ, Kuhlmann U, Sheppard A, Qin T-K, Barratt BIP, Harrison L, Mason PG, Parker D, Flanders RV, Goolsby J (2007) Review of invertebrate biological control agent regulation in Australia, New Zealand, Canada and the USA: recommendations for a harmonized European system. J Appl Entomol 132:1-35

Ingels B, De Clercq P (2011) Effect of size, extraguild prey and habitat complexity on intraguild interactions: a case study with the invasive ladybird Harmonia axyridis and the hoverfly Episyrphus balteatus. BioControl. doi:10.1007/ s10526-011-9363-9

Kenis M, Branco M (2010) Impact of alien terrestrial arthropods in Europe. BioRisk 4:51-71

Kenis M, Roy HE, Zindel R, Majerus MEN (2008) Current and potential management strategies against Harmonia axyridis. BioControl 53:235-252

Kenis M, Auger-Rozenberg MA, Roques A, Timms L, Pere C, Cock M, Settele J, Augustin S, Lopez-Vaamonde C (2009) Ecological effects of invasive alien insects. Biol Invasions 11:21-45

Kindlmann P, Ameixa OMCC, Dixon AFG (2011) Ecological effects of invasive alien species on native communities, with particular emphasis on the interactions between aphids and ladybirds. BioControl. doi:10.1007/s10526011-9384-4

Koch RL, Galvan TL (2008) Bad side of a good beetle: the North American experience with Harmonia axyridis. BioControl 53:23-35

Koyama S, Majerus MEN (2008) Interactions between the parasitoid wasp Dinocampus coccinellae and two species of coccinellid from Japan and Britain. BioControl 53: 253-264

Lawson Handley L-J, Estoup A, Evans DM, Thomas CE, Lombaert E, Facon B, Aebi A, Roy HE (2011) Ecological genetics of invasive alien species. BioControl. doi: 10.1007/s10526-011-9386-2

Lombaert E, Malausa T, Devred R, Estoup A (2008) Phenotypic variation in invasive and biocontrol populations of the harlequin ladybird, Harmonia axyridis. BioControl 53:89-102

Majerus MEN, Strawson V, Roy HE (2006) The potential impacts of the arrival of the Harlequin ladybird, Harmonia axyridis (Pallas) (Coleoptera: Coccinellidae), in Britain. Ecol Entomol 31:207-215

Nedved O, Pekár S, Bezděčka P, Líznarová E, Řezáč M, Schmitt M, Sentenská L (2011) Ecology of Arachnida alien to Europe. BioControl. doi:10.1007/s10526-0119385-3 
Osawa N (2011) Ecology of Harmonia axyridis in natural habitats within its native range. BioControl. doi:10.1007/ s10526-011-9382-6

Pell JK, Baverstock J, Roy HE, Ware RL, Majerus MEN (2008) Intraguild predation involving Harmonia axyridis: a review of current knowledge and future perspectives. BioControl 53:147-168

Poutsma J, Loomans AJM, Aukema B, Heijerman T (2008) Predicting the potential geographical distribution of the harlequin ladybird, Harmonia axyridis, using the CLIMEX model. BioControl 53:103-125

Rabitsch W (2011) The hitchhiker's guide to alien ant invasions. BioControl. doi:10.1007/s10526-011-9370-x

Roy HE, Migeon A (2010) Ladybeetles (Coccinellidae). BioRisk 4:293-313

Roy H, Wajnberg E (2008) From biological control to invasion: the ladybird Harmonia axyridis as a model species. BioControl 53:1-4

Roy HE, Brown PMJ, Rothery P, Ware RL, Majerus MEN (2008) Interactions between the fungal pathogen Beauveria bassiana and three species of coccinellid: Harmonia axyridis, Coccinella septempunctata and Adalia bipunctata. BioControl 53:265-276

Roy HE, Lawson Handley L-J, Schonrogge K, Poland RL, Purse BV (2011a) Can the enemy release hypothesis explain the success of invasive alien predators and parasitoids? BioControl. doi:10.1007/s10526-011-9349-7

Roy HE, Roy DB, Roques A (2011b) Inventory of terrestrial alien arthropod predators and parasites established in Europe. BioControl. doi:10.1007/s10526-011-9355-9

Roy HE, Rhule E, Harding S, Lawson-Handley L, Poland RL, Riddick EW and Steenberg T (2011c) Living with the enemy: parasites and pathogens of the ladybird Harmonia axyridis. BioControl. doi:10.1007/s10526-011-9387-1

Roy HE, Brown PMJ, Frost R, Poland RP (2011d) Ladybirds (Coccinellidae) of Britain and Ireland. Field Studies Council for the Biological Records Centre, Shrewsbury

Shea K, Chesson P (2002) Community ecology theory as a framework for biological invasions. Trends Ecol Evol 17:170-176

Sloggett JJ, Magro A, Verheggen FJ, Hemptinne JL, Hutchison WD, Riddick EW (2011) The chemical ecology of Harmonia axyridis. BioControl. doi:10.1007/s10526-011-9376-4

Soares AO, Borges I, Borges PAV, Labrie G, Lucas E (2008) Harmonia axyridis: What will stop the invader? BioControl 53:127-145

Torchin ME, Lafferty KD, Dobson AP, McKenzie VJ, Kuris AM (2003) Introduced species and their missing parasites. Nature 421:628-630

van Lenteren JC, Bale J, Bigler E, Hokkanen HMT, Loomans AM (2006) Assessing risks of releasing exotic biological control agents of arthropod pests. Annu Rev Entomol 51:609-634

Wajnberg E, Scott JK, Quimby PC (2001) Evaluating indirect ecological effects of biological control. CAB International, Wallingford, p 288

Ware RL, Majerus MEN (2008) Intraguild predation of immature stages of British and Japanese coccinellids by the invasive ladybird Harmonia axyridis. BioControl 53: 169-188

\section{Author Biographies}

Helen E. Roy is an ecologist leading zoological research in the Biological Records Centre at the NERC Centre for Ecology \& Hydrology (UK). The focus of her research is insect community interactions with particular emphasis on the effects of environmental change. She is convenor of the IOBC/WPRS Working Group "Benefits and Risks of Exotic Biological Control Agents" which was the impetus for this special issue of BioControl. She is currently leading the development of the GB Non-Native Species Information Portal. She is an associate editor of BioControl.

Patrick De Clercq is an agricultural entomologist and professor at Ghent University, Belgium. His research group focuses on the integrated control of arthropod pests, with emphasis on the potential of predatory insects and mites for augmentative biological control. His special attention goes out to risk assessment for biological control agents and to the development of rearing systems for predatory arthropods. He is a member of the joint IOBC/European and Mediterranean Plant Protection (EPPO) Panel on Biological Control Agents and a co-convenor of the IOBC Global Working Group on "Mass Rearing and Quality Assurance". He is an associate editor of BioControl and the Journal of Plant Diseases and Protection.

Lori-Jayne Lawson Handley is a lecturer at the University of Hull. Her research interests centre on molecular ecology and she has published widely in this field. She has a particular interest in using molecular techniques to increase understanding of invasive alien species and has been effective at applying the latest tools to key questions in relation to routes of invasion.

Remy L. Poland is a secondary school teacher (biology) at Clifton College. She has extensive research expertise in intraguild interactions. Her research on the harlequin ladybird and natural enemy interactions is ongoing. She co-leads the UK Ladybird Survey with Helen Roy and Peter Brown.

John J. Sloggett is an independent research ecologist who has worked with ladybirds for over 17 years. His interests include the evolution of habitat and dietary breadth and chemical defence. He has worked with the ladybird Harmonia axyridis since first observing its effects as an alien invader while a researcher at the University of Kentucky, in 2005.

Eric Wajnberg is a population biologist specialized in behavioural ecology, statistical modelling and population genetics. He develops theoretical approaches-mainly based on Monte Carlo simulations coupled with Genetic Algorithms - and experiments are conducted in order to verify the predictions obtained. He is also an expert in biological control (past Secretary General of the IOBC), with more than 25 years of work with insect parasitoids. He has already published several books on biological control and behaviour ecology and is the Editor in Chief of BioControl. 